Marius Simion Motogna

Dan Moldovanu

Florin Mariasiu

https://doi.org/10.21278/TOF.42406

ISSN 1333-1124

eISSN 1849-1391

\title{
NUMERICAL ANALYSIS OF FUEL FLOW PATTERNS AT THE NOZZLE EXIT CONSIDERING DIFFERENT FUELS AND OPERATING PARAMETERS OF A DIESEL ENGINE
}

\begin{abstract}
Summary
The paper presents a numerical study (Eulerian multiphase approach) on the influence of physical characteristics of different fuels (density and dynamic viscosity) on the fuel flow pattern at the injection nozzle exit considering different fuels and operating parameters of a diesel engine (fuel temperature and compression ratio). A new term, Nozzle Uniformity Coefficient (NUC) was introduced to define the fluid flow pattern at the injection nozzle exit and to correlate its value with a further development of the spray in the combustion chamber. The results of the analysis show that the structure of the fluid flow pattern is the most homogeneous in the case of low fuel temperatures and low back pressures. Fuel velocities have an immediate effect on the spray development, the air-fuel mixing process, and the depth of jet penetration into the combustion chamber. The average values of biodiesel fuel velocities are lower compared to those of diesel fuel. In view of the increasing use of fuels from renewable sources (biofuels), a logical conclusion is that it is necessary to correlate the injection system components with their physicochemical properties.
\end{abstract}

Key words: $\quad$ fuel, diesel engine, flow, nozzle, simulation.

\section{Introduction}

Presently, attention world-wide is drawn to the reduction of pollution caused by the transport sector. One of the short-term solutions applied at the European level is to use an increasing proportion of renewable fuels mixed with the fossil fuel [1]. Researches in this domain have already shown that there is a high degree of direct compatibility between the biofuel and internal combustion engines that are already in use and which, more importantly, have been designed, developed and built for the use of fossil fuels.

However, the reduction in pollution caused by compression-ignition engines fuelled with biodiesel is accompanied with decreased engine performance largely due to the lower calorific value of biofuels compared to fossil fuels (petroleum-diesel). The effect of the compression ratio and biodiesel blends on the performance and emission characteristics of a 
Numerical Analysis of Fuel Flow Patterns at the Nozzle Exit Considering Different Fuels and Operating Parameters of a Diesel Engine

diesel engine was analysed in [2]. It was found that the brake thermal efficiency of the diesel engine is considerably higher with the NB20 blend than with diesel at compression ratios of 18, 20, and 22. Further, experiments showed that the influences of different injection parameters (pressure, diesel fuel mass flow, and injection timing) are interconnected [3]. An optimized performance of the engine can only be obtained with an adequate combination of all three injection parameters. Novel bioethanol fumigation applications for the fuelling of a dual-fuel diesel engine were experimentally investigated [4]. A major average reduction of $31.5 \% \mathrm{x}$ in the NOx emission together with a slight increase in the engine thermal efficiency was achieved using NB20 in comparison with the use of the B5 blend.

A way to improve the thermal efficiency of the engine fuelled with biofuels is to increase the efficiency of the combustion process. The combustion process is directly related to the injection and air-fuel mixing processes. A good and homogeneous fuel jet structure, small fuel particles, the penetration depth of the jet correlated with the geometric shape of the combustion chamber and the spray pattern development are just a few requirements to be met by a high-performance injection system [5]. All of the above requirements directly depend on the physical characteristics of the fuel, the geometric characteristics of the injector, and the operating parameters of the injection system (injection pressure). Currently, there are several research directions and results regarding the influence of fuel characteristics and injection equipment on the fuel jet structure, which are briefly presented as follows.

A gradual increase in the injection pressure from $40 \mathrm{MPa}$ to $140 \mathrm{MPa}$ has a direct influence on the fuel spray structure, which tends to become finer while the jet penetration depth becomes greater [6]. It was also discovered that the ambient temperature slightly affects the cone penetration depth and some improvements were noted when the combustion chamber temperature increased from $500 \mathrm{~K}$ to $700 \mathrm{~K}$. In high ambient temperatures, fuel evaporates more easily and spontaneous combustion occurs.

The influence of fuel properties on the fuel flow pattern during the injection process was investigated for high pressure injection systems [7]. The study was focused on the dynamic structure of the spray. For that purpose, the conventional diesel fuel and biofuels were used and compared and the geometry of the nozzle was altered. The results show that the increased values of viscosity and density corresponding to the biofuels lead to a decrease in the injection velocity in comparison with the conventional diesel results. This effect is more pronounced in the cases of single-hole injectors because the biodiesel slowed down the flow breakup and increased the intact core length that caused lower velocity decay rate and turbulence intensity along the spray centre.

Further, some other parameters that have been proved to have a big influence on the internal fluid flow and the injection process, i.e. cavitation and the back pressure, were taken into consideration [8]. Using a verified 3D injector model, the researchers developed numerical simulations which showed that, for a given injection pressure, cavitation occurs with a decrease in back pressure. The scientists also reported that the super-cavitation process induces an increase in the values of turbulence kinetic energy, which results in the acceleration of the flow. Thus, the outlet velocity of the liquid is increased. There is another study dealing with the effect of cavitation on fuel flow patterns in the injection nozzle; this study considers the back pressure effects [9]. The research combined computational and experimental studies and linked the occurrence and development of cavitation to the back pressure, showing that the two quantities are inversely proportional. 
The effects of heavy fuel oil properties on spray characteristics were investigated using a common-rail injection system taking into account the temperature of fuel [10]. The conclusions of this study were that with an increasing fuel temperature, the density of the fuel decreases linearly while the dynamic viscosity decreases exponentially. The injection time delay was increased as the fuel temperature rose and the spray tip penetration depth decreased under high ambient density conditions (the loss of the momentum of fuel droplets because of gas molecules). The research also revealed that the spray characteristics are influenced by the fuel properties (the jet penetration depth decreased with an increase in the fuel temperature). More details about the differences between spraying cone geometries, investigated in different cases and by using different biofuels such as rapeseed oil and fatty acid methyl esters and blends of these fuels in different proportions, can be found in [11]. The results show that the most significant parameters of the jet spray cone are viscosity, surface tension, and density, because an increase in the values of these parameters results in a decrease in the values of the spray cone angle and the spray tip penetration depth.

It can be noted that the research presented in the literature quoted above only considered the developed structure of the fuel spray in the combustion chamber and the relation of its characteristics to the selected factors influencing the fuel spray structure, such as density, viscosity, temperature, injection and back pressure, and nozzle geometry. The present paper proposes a numerical study of the fuel spray formation and its development from the early, primary phase at the exit of the injection nozzle from the aspect of the fuel flow pattern. The main objective of research was to analyse the fuel flow pattern from the exit of injection nozzle with respect to different fuels and the operating parameters of a diesel engine. The fuel flow exit pattern was characterized by means of a new parameter, the Nozzle Uniformity Coefficient (NUC), which can show the spray homogeneity and the spatial development structure.

\section{Material and methods}

In order to investigate the effects of the fuel characteristics and the engine operating parameters on the nozzle fuel flow pattern, two different fuels were chosen: diesel fuel (D) and rapeseed methyl ester (RME). The characteristics of these fuels and the main boundary conditions of the computational simulation are presented in Table 1.

For the analysis of the obtained results, the new coefficient that can characterize the uniformity of the velocity field of the fuel at the outlet of the injector has been used. The nozzle uniformity coefficient is defined as a ratio between the two areas with fuel-related characteristics at the injection nozzle exit (Eq.1).

$$
N U C=\frac{\text { Area }\left[v_{a v g}, v_{\max }\right]}{\text { Area }\left[v_{\min }, v_{\max }\right]},
$$

where: $v_{\min }, v_{\max }$ and $v_{\text {avg }}$ represent the minimum velocity, maximum velocity, and average velocity of the fuel at the nozzle exit, respectively. 
Table 1 Fuel characteristics and boundary conditions

\begin{tabular}{|c|c|c|c|c|}
\hline \multirow{3}{*}{ Fuel } & Injection pressure & Fuel temperature & Density & Dynamic viscosity \\
\cline { 2 - 5 } & $\mathrm{MPa}$ & ${ }^{\circ} \mathrm{C}$ & $\mathrm{kg} / \mathrm{m}^{3}$ & $\mathrm{~Pa} \cdot \mathrm{s} \mathrm{x} 10^{-3}$ \\
\hline \multirow{3}{*}{$\begin{array}{c}\text { Diesel } \\
\text { (D) }\end{array}$} & \multirow{3}{*}{150} & 40 & 890 & 2.42 \\
\cline { 3 - 5 } & & 60 & 809.3 & 1.73 \\
\cline { 3 - 5 } & & 80 & 796 & 1.23 \\
\hline \multirow{3}{*}{$\begin{array}{c}\text { Biodiesel } \\
(\mathrm{RME})\end{array}$} & \multirow{3}{*}{150} & 100 & 780 & 0.913 \\
\cline { 3 - 5 } & & 40 & 884 & 4.31 \\
\cline { 3 - 5 } & & 60 & 873.3 & 2.7 \\
\cline { 3 - 5 } & & 100 & 860 & 1.9 \\
\hline
\end{tabular}

As it can be seen, the value of NUC varies between 0 and 1 . If the value of NUC tends to 0 , the velocity of the fuel droplets is low, resulting in large droplets in the spray jet structure. This leads to a slow and poor vaporization and a higher degree of combustion chamber turbulence is required. Similarly, if NUC tends to 1, the droplet velocity is high at the nozzle exit and the droplet diameters are smaller as a consequence. This leads to a faster air-fuel mixture formation and low turbulence is required in the combustion chamber.

The AVL FIRE CFD code software package was used to simulate the flow of fuel in the injection nozzle and a multi-fluid model was adopted for simulating the multiphase flow of fuel (Eulerian-Eulerian approach) caused by the effect of cavitation. The multi-fluid model calculates the set of conservation equations (momentum and energy) for liquid and gas phases by using the coupling method chosen in the given interface. In turbulent conditions, fluctuating parameters are averaged using the RANS methods and for this study, the k-zeta-f model was considered [12]. The model was experimentally validated in the previous studies of the authors, with average errors of results between $1.48 \%$ and $2.45 \%$ [12].

A VCO-type multi-hole injector was taken into consideration, with its geometrical model and characteristics transferred to a computational model, presented in Fig. 1. Because the injector holes were in a symmetric distribution along the axis of the injector and because they were also in a circumferential distribution, only a $30^{\circ}$ segment model was adopted for the simulation. The injector model was of a joined moving mesh type to enable the movement of the injector needle in the injection process to be captured. The cell density was chosen from several simulations that yielded the same results and a good simulation time. It should be noted that if the grid has bigger cells, the precision is affected and if the grid is very fine, the simulation time is affected. A moving grid was built to achieve a mesh of 180,522 cells. The results were considered for a simulation time of $1.2 \mathrm{~ms}$, with a maximum injector needle lift of $0.5 \mathrm{~mm}$. The hole was meshed with 116,448 cells and the body and the rest of the sac were meshed with 74,564 cells. The domain of the constant-volume vessel consisted of approximately 400,000 cells, characterized by a constant mesh size of $0.30 \mathrm{~mm}$. The angle between the axis of the cylindrical nozzle and the injector cone was set at $75^{\circ}$ and the length and the exit diameter of the nozzle were 1.05 and $0.22 \mathrm{~mm}$, respectively.

The boundary conditions specify the physical properties of the faces on the volume mesh. The boundaries of the volume mesh include the inlet, the outlet and the wall boundary. As for cavitation, the boundary conditions will require specifications for two phases (liquid and gas) [12]. For both phases, the inlet boundary conditions, i.e. the turbulent kinetic energy and the turbulent length scale, were adopted as $0.1 \mathrm{~m}$ and $0.001 \mathrm{~m}^{2} / \mathrm{s}^{2}$, respectively. For the outlet boundary condition, the fixed volume fraction was adopted as 0.999 for the liquid phase 
and as $10^{-6}$ for the gas phase [12]. Pressure boundary conditions were considered for the inlet and the outlet of the injection nozzle. The pressure at the inlet of the nozzle was set to $150 \mathrm{MPa}$ (at the injected fuel temperature between $40^{\circ} \mathrm{C}$ and $100^{\circ} \mathrm{C}$, in steps of $20^{\circ} \mathrm{C}$ ) and the back pressure was set between 0.5 and $3.5 \mathrm{MPa}$ (steps of $1 \mathrm{MPa}$ ).

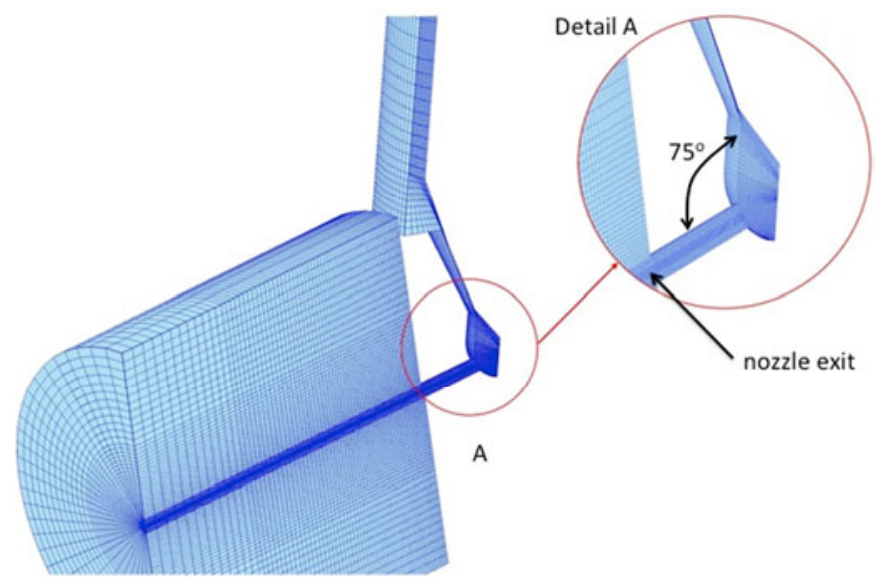

Fig. 1 A model of the injector

Other boundary conditions are the symmetry faces because the simulation was carried out on a half-model to reduce the simulation time and resources. For the activation of equations, the simulation was carried out using the active momentum and continuity, the volume fraction, and the k-zeta-f turbulence model. The k-zeta-f turbulence model was adopted because it had been found to be particularly effective in predicting near wall effects on the turbulence level. The liquid was set to incompressible and the wall heat transfer was set to Standard. The convergence criteria were set to maximum 100 and minimum 3 iterations with normalized residuals. The solution convergence criterion is achieved when the pressure, momentum, turbulence kinetic energy, and volume fraction residuals decrease below a value of $1 \mathrm{e}-4$.

The AVL FIRE CFD code uses the k-zeta-f model, with the aim of improving numerical stability by solving the transport equation for the velocity scale ratio $\zeta=\overline{v^{2}} / k$. The eddyviscosity is obtained from Eq. 2:

$$
v_{t}=C_{\mu} \zeta \frac{k^{2}}{\varepsilon}
$$

The turbulent time scale $T$ and the length scale $L$ are given by Eq.3 and 4:

$$
\begin{aligned}
& T=\max \left(\min \left(\frac{k}{\varepsilon}, \frac{a}{\sqrt{6} C_{\mu}|S| \zeta}\right), C_{T}\left(\frac{v}{\varepsilon}\right)^{1 / 2}\right), \\
& T=C_{L} \max \left(\min \left(\frac{k^{3 / 2}}{\varepsilon}, \frac{k^{1 / 2}}{\sqrt{6} C_{\mu}|S| \zeta}\right), C_{\eta} \frac{v^{3 / 4}}{\varepsilon^{1 / 4}}\right),
\end{aligned}
$$

where $C_{\mu}=0.22, C_{T}=6, C_{L}=0.36$ and $C_{\eta}=85$.

\section{Results and discussions}

The main goal of this study is to monitor the impact of various parameters on the fuel flow pattern. Velocity is one of the most important factors that influence the future structure and geometry of the spray jet, but an accumulation of other factors was also taken into consideration (e.g. cavitation). Table 2 shows the results related to the average velocities measured for both fuels at the nozzle exit. 
For the numerical simulation, low values of the back pressure were used in spite of the fact that those values would not be reached in a real situation. This was done in order to highlight the influence of the back pressure on the fuel flow pattern at the nozzle exit.

Table 2 Influence of back pressure and fuel temperature on the average velocity of the fuel

\begin{tabular}{|c|c|c|c|}
\hline \multirow[t]{2}{*}{$\begin{array}{c}\text { Back pressure } \\
/ \mathrm{MPa}\end{array}$} & \multirow[t]{2}{*}{$\begin{array}{l}\text { Fuel temperature } \\
\qquad /{ }^{\circ} \mathrm{C}\end{array}$} & \multicolumn{2}{|c|}{$\begin{array}{l}\text { Average velocity } \\
\qquad / \mathrm{m} / \mathrm{s}\end{array}$} \\
\hline & & Diesel & Biodiesel \\
\hline \multirow{4}{*}{0.5} & 40 & 163.55 & 126.50 \\
\hline & 60 & 172.70 & 147.50 \\
\hline & 80 & 185.65 & 162.40 \\
\hline & 100 & 196.50 & 175.05 \\
\hline \multirow{4}{*}{1.5} & 40 & 152.70 & 110.50 \\
\hline & 60 & 161.95 & 136.00 \\
\hline & 80 & 172.50 & 147.60 \\
\hline & 100 & 175.10 & 166.40 \\
\hline \multirow{4}{*}{2.5} & 40 & 147.55 & 106.50 \\
\hline & 60 & 156.00 & 131.20 \\
\hline & 80 & 168.25 & 146.20 \\
\hline & 100 & 179.40 & 158.35 \\
\hline \multirow{4}{*}{3.5} & 40 & 143.25 & 97.50 \\
\hline & 60 & 151.40 & 127.65 \\
\hline & 80 & 163.05 & 140.50 \\
\hline & 100 & 172.75 & 150.50 \\
\hline
\end{tabular}

The structure of the fuel flow pattern for each fuel and the variable influence of the considered parameters on its structure are shown in Figures 2-5. Based on the results obtained from the simulation and using Equation 1, the variations in the values of NUC are obtained in dependence on the variations in the values of the parameters taken into account for the simulation (fuel temperature and back pressure). These variations in the values of NUC are shown in Figures 6-9.

It can be seen that both the fuel temperature and the back pressure influence directly the structure of the fuel flow at the exit of the injector (directly by the effect of temperature on the fuel density and viscosity and indirectly on the cavitation in the nozzle).

The values of NUC confirm the experimental results, on the behaviour of the biofuel spray injected into the engine combustion chamber obtained by other researchers in $[13,14]$. The value of NUC is lower for biofuels than for diesel, which means the fuel flow pattern is characterized by the low speed of fuel droplets. This results in slow fuel vaporization with a direct influence on the increase in the depth of jet penetration into the combustion chamber.

Also, the air-fuel mixture is more difficult to achieve than in the case with the diesel fuel because stronger turbulence is needed in the combustion chamber to reduce the time of mixture formation; this has which has an immediate effect on the speed and power of the engine $[2,4,5]$.

From the graphical results shown in Figures 2-5, one can conclude that the fuel velocity is not spread homogeneously on the output section of the nozzle exit. Maximum values were found at the middle-bottom side of the section, while minimum values were found at the top side and near the outlines of the nozzle. 

the Nozzle Exit Considering Different Fuels and Operating Parameters of a Diesel Engine

\begin{tabular}{|c|c|c|c|c|c|}
\hline Fuel & $\mathrm{T}=40^{\circ} \mathrm{C}$ & $\mathrm{T}=60^{\circ} \mathrm{C}$ & $\mathrm{T}=80^{\circ} \mathrm{C}$ & $\mathrm{T}=100^{\circ} \mathrm{C}$ & \\
\hline \multicolumn{6}{|l|}{ Diesel } \\
\hline Maximum value $/ \mathrm{m} / \mathrm{s}$ & 183.2 & 192.9 & 206 & 217 & \\
\hline Minimum value / m/s & 143.9 & 152.5 & 165.3 & 176 & 189 \\
\hline \multicolumn{6}{|l|}{ Biodiesel } \\
\hline Maximum value $/ \mathrm{m} / \mathrm{s}$ & 140 & 165 & 181.9 & 194.7 & \\
\hline Minimum value $/ \mathrm{m} / \mathrm{s}$ & 113 & 130 & 142.9 & 155.4 & \\
\hline
\end{tabular}

Fig. 2 Fuel flow pattern at the nozzle exit; back pressure $=0.5 \mathrm{MPa}$

\begin{tabular}{|c|c|c|c|c|c|}
\hline Fuel & $\mathrm{T}=40^{\circ} \mathrm{C}$ & $\mathrm{T}=60^{\circ} \mathrm{C}$ & $\mathrm{T}=80^{\circ} \mathrm{C}$ & $\mathrm{T}=100^{\circ} \mathrm{C}$ & \\
\hline \multicolumn{6}{|l|}{ Diesel } \\
\hline Maximum value $/ \mathrm{m} / \mathrm{s}$ & 175.7 & 185.5 & 199.1 & 212.3 & \\
\hline Minimum value $/ \mathrm{m} / \mathrm{s}$ & 129.7 & 138.4 & 151.1 & 162.7 & 169 \\
\hline \multicolumn{6}{|l|}{ Biodiesel } \\
\hline Maximum value $/ \mathrm{m} / \mathrm{s}$ & 133 & 158 & 175.9 & 189.8 & \\
\hline Minimum value $/ \mathrm{m} / \mathrm{s}$ & 88.2 & 114.1 & 129.3 & 143.4 & \\
\hline
\end{tabular}

Fig. 3 Fuel flow pattern at the nozzle exit; back pressure $=1.5 \mathrm{MPa}$ 
Operating Parameters of a Diesel Engine

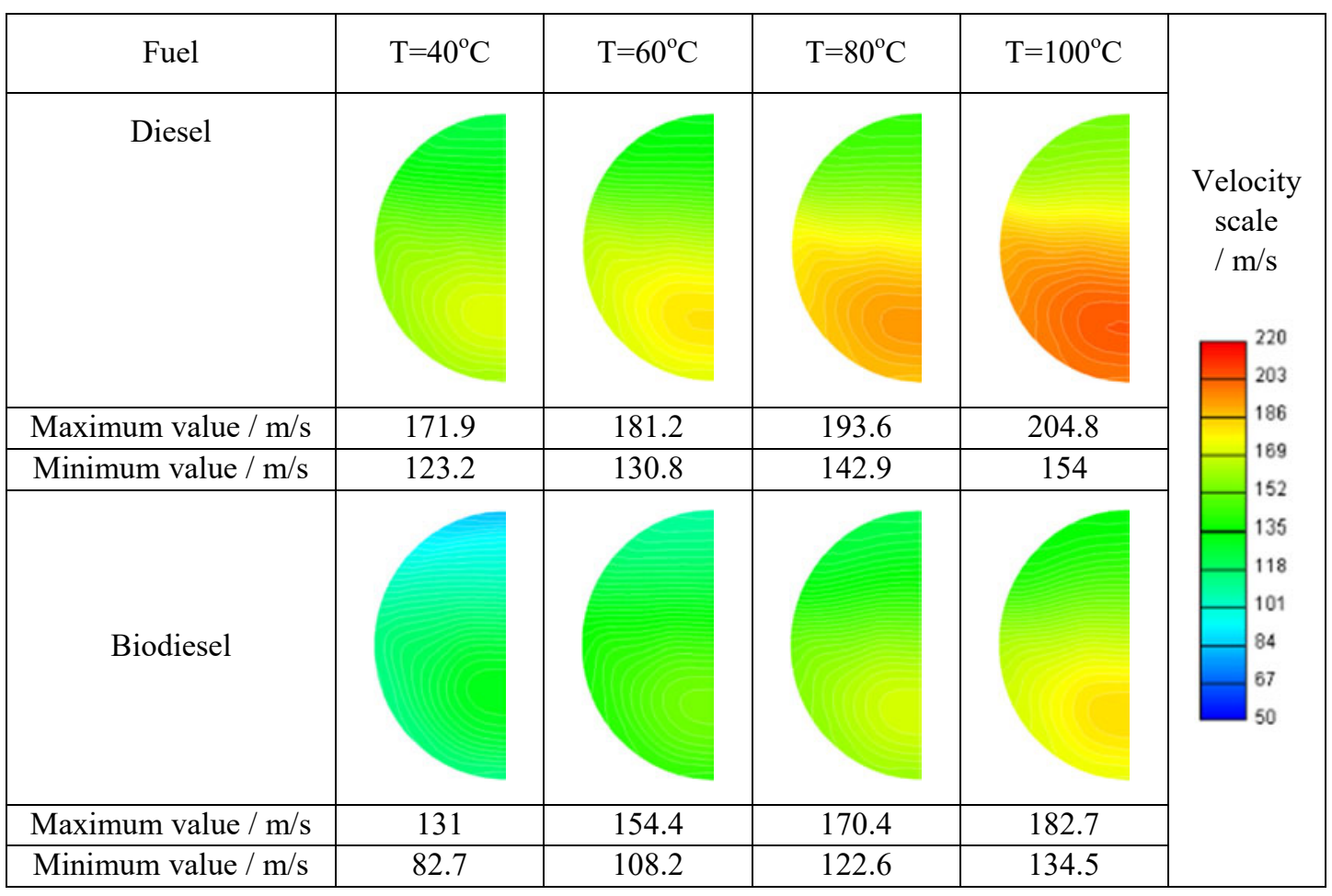

Fig. 4 Fuel flow pattern at the nozzle exit; back pressure $=2.5 \mathrm{MPa}$

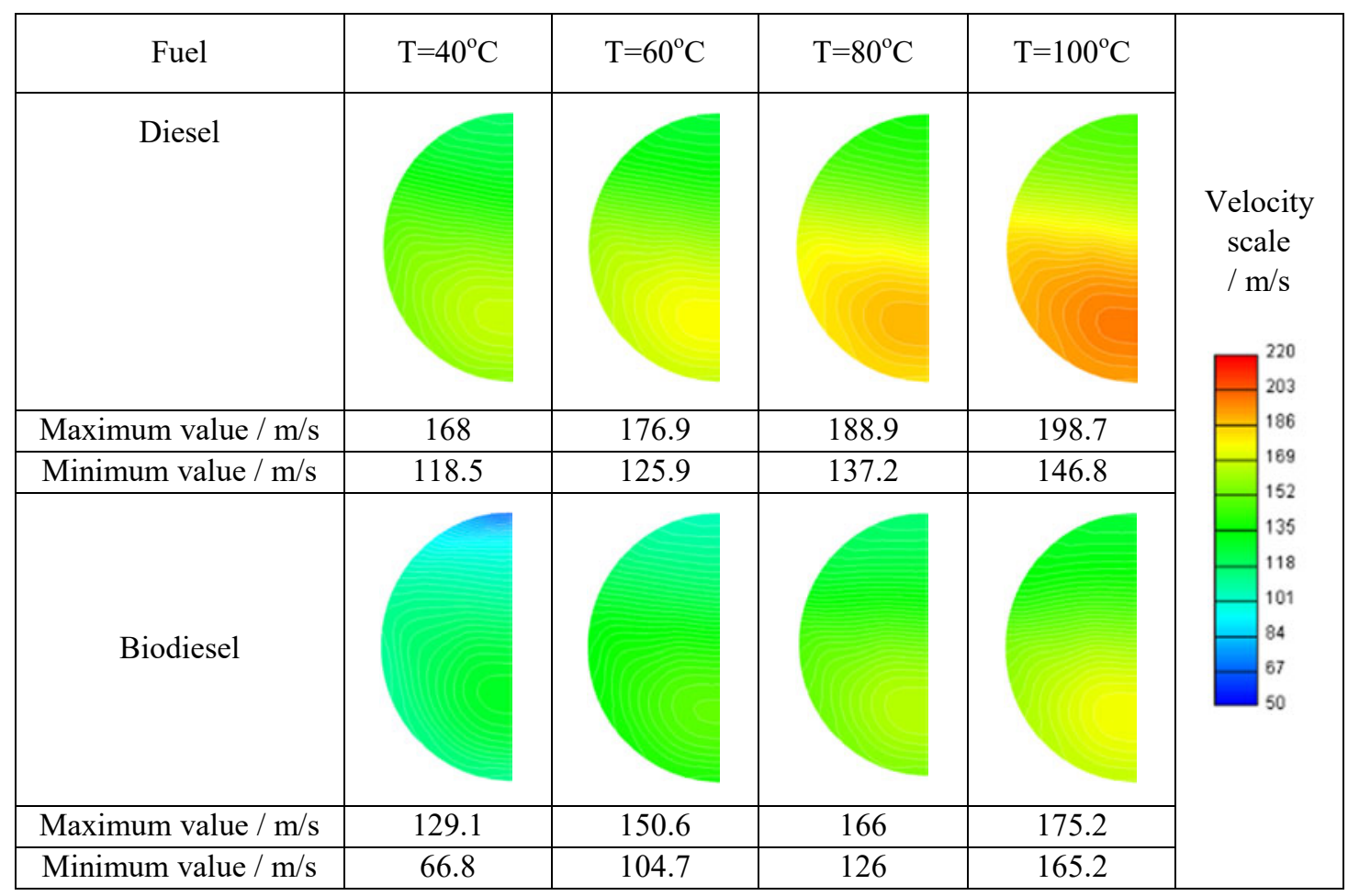

Fig. 5 Fuel flow pattern at the nozzle exit; back pressure $=3.5 \mathrm{MPa}$ 

the Nozzle Exit Considering Different Fuels and Operating Parameters of a Diesel Engine

As a rule, this inhomogeneous distribution occurs in every case for both fuels. A possible explanation can be the influence of cavitation which occurs at the entrance section of the hole due to the inner geometry of the nozzle, so velocities increase at the bottom side as an effect of the flowing section, as seen at the hole exit. Maximum velocity is found at the maximum temperature $\left(100^{\circ} \mathrm{C}\right)$ and the lowest back pressure $(0.5 \mathrm{MPa}$ back pressure in the case of diesel fuel). This behaviour can be easily deduced from previous conclusions stating that with an increase in temperature, the dynamic viscosity decreases. In combination with a low resistant pressure, this leads to an easier flow in the nozzle. In those cases, very intense cavitation is expected.

By comparing the two fuels used in the study, it can also be concluded that in every situation the output velocity of the conventional diesel fuel is higher than that of biodiesel. The differences between the values of output velocity of the two fuels are increasingly bigger as the fuel temperature and back pressure decrease. The main factor influencing the output velocity of biodiesel is its dynamic viscosity, which is temperature-dependent and which increases very steeply when the temperature falls below $60^{\circ} \mathrm{C}$. As a direct effect of this, the following can be expected when biodiesel is used: less intense cavitation in the nozzle, a more compact shape of the injection jet spray, reduced penetration tip and increased size of droplets in the spray. This indicates again that, in contrast with the diesel fuel, the injection process with biodiesel is not very stable because it is significantly influenced by external parameters such as temperature and intake pressure. Nevertheless, based on the obtained results, there is a similarity between the values of the diesel fuel speed at the nozzle exit at $60^{\circ} \mathrm{C}$ and those of the biodiesel fuel at $100^{\circ} \mathrm{C}$ (Table 3).

Comparative variations in the values of NUC for the considered fuels and functional conditions (fuel temperature and back pressure) are presented in Figures 6-9.

Table 3 NUC values for Diesel and Biodiesel fuels

\begin{tabular}{|c|c|c|c|}
\hline \multirow{2}{*}{$\begin{array}{c}\text { Back pressure } \\
/ \mathrm{MPa}\end{array}$} & \multicolumn{2}{|c|}{ NUC coefficient } & \multirow{2}{*}{$\begin{array}{c}\text { Differences } \\
(\%)\end{array}$} \\
\cline { 2 - 3 } & $\begin{array}{c}\text { Diesel } \\
@ 60^{\circ} \mathrm{C}\end{array}$ & $\begin{array}{c}\text { Biodiesel } \\
@ 100^{\circ} \mathrm{C}\end{array}$ & \\
\hline 0.5 & 0.681 & 0.704 & 3.38 \\
\hline 1.5 & 0.516 & 0.533 & 3.29 \\
\hline 2.5 & 0.495 & 0.511 & 3.23 \\
\hline 3.5 & 0.260 & 0.268 & 3.08 \\
\hline
\end{tabular}

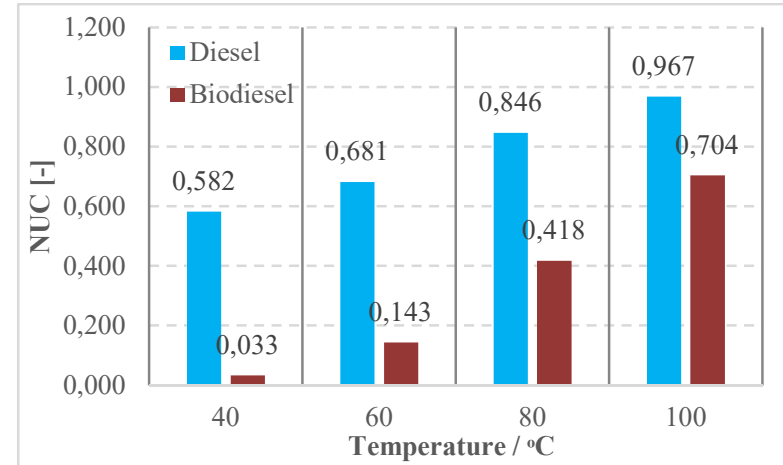

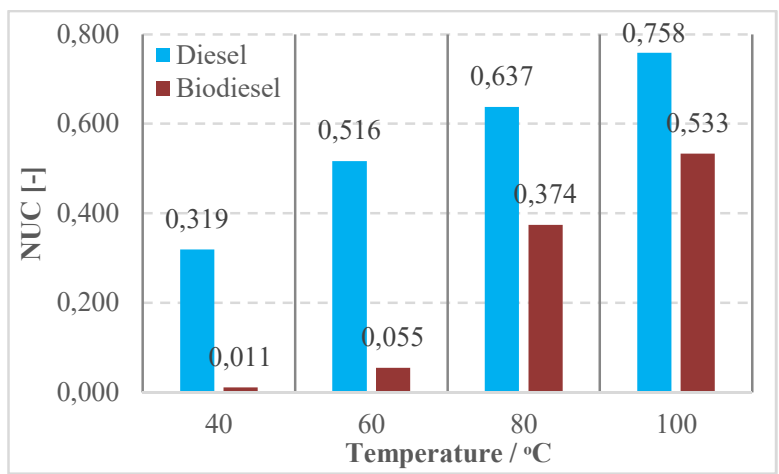

b

Fig. 6 Variation in the values of NUC at $p_{b p}=0.5 \mathrm{MPa}(\mathrm{a})$ and $\mathrm{p}_{\mathrm{bp}}=1.5 \mathrm{MPa}(\mathrm{b})$ 
Numerical Analysis of Fuel Flow Patterns at the Nozzle Exit Considering Different Fuels and Operating Parameters of a Diesel Engine

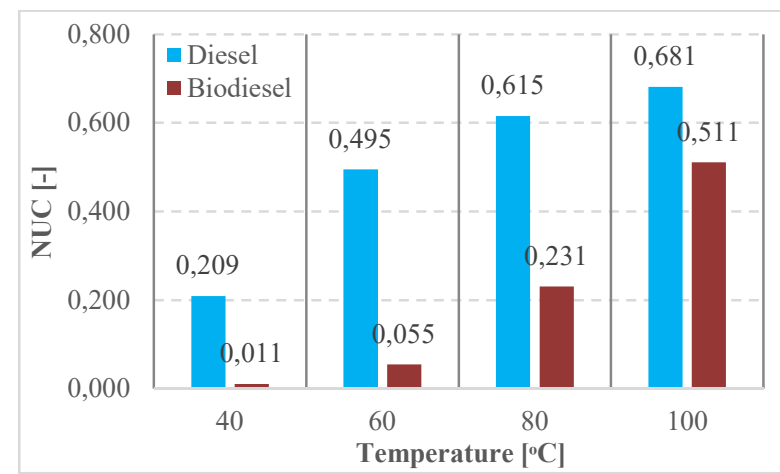

a

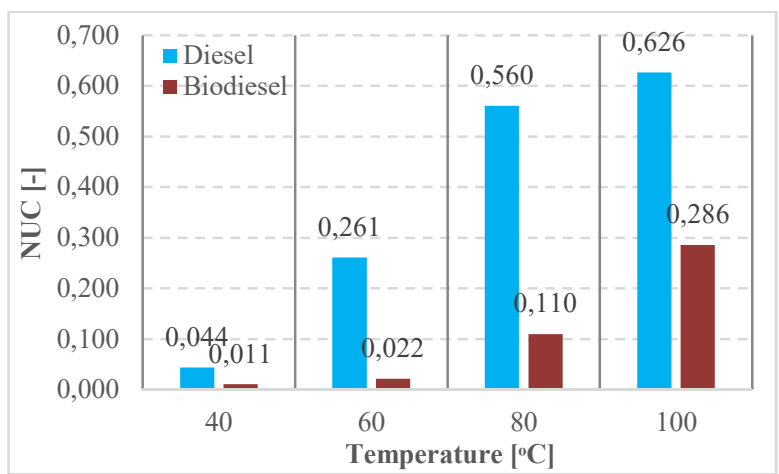

$\mathrm{b}$

Fig. 7 Variation in the values of NUC at $\mathrm{p}_{\mathrm{bp}}=2.5 \mathrm{MPa}$ (a) and $\mathrm{p}_{\mathrm{bp}}=3.5 \mathrm{MPa}$ (b)

By comparing the variation in the values of NUC for the diesel fuel and biofuel and taking into consideration the factors that influence it, one can say that NUC increases in a direct correlation with an increase in the fuel temperature and with an increase in the back pressure in the combustion chamber.

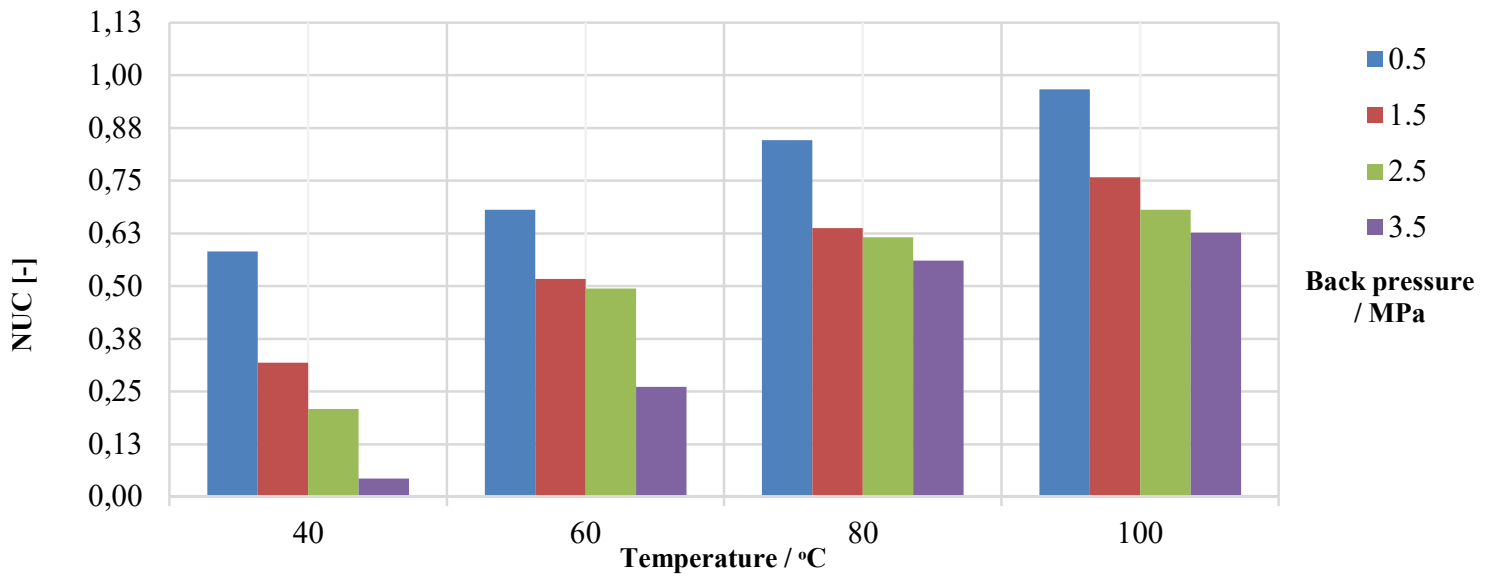

Fig. 8 Variation in the values of NUC for diesel (all temperatures and back pressures)

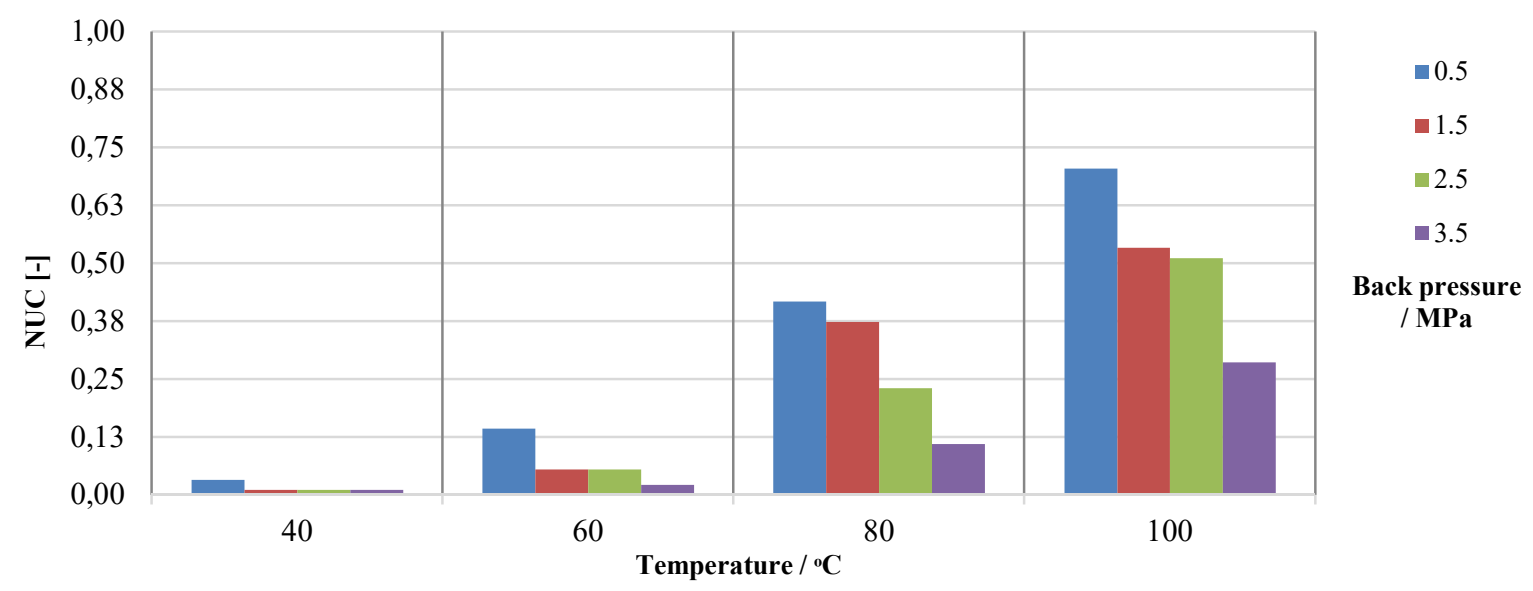

Fig. 9 Variation in the values of NUC for biodiesel (all temperatures and back pressures) 
the Nozzle Exit Considering Different Fuels and

Operating Parameters of a Diesel Engine

\section{Conclusions}

Based on the results obtained from the numerical analysis of the physical characteristics of fuels and the influence of compression ignition engine operating parameters on the homogeneity of the fuel flow pattern at the injection nozzle exit, the following general conclusions can be drawn:

- The formation of a homogeneous and symmetrical fuel spray structure at the injection nozzle exit requires homogeneous fuel flow pattern in its entire section. In practice, this is not possible with injectors used in compression ignition engines because of the occurrence of cavitation in the injection nozzle. Besides the influence of cavitation on the fuel flow pattern at the exit of the injection nozzle, the fuel temperature and the back pressure from the combustion chamber are studied as important parameters in the initial formation of the fuel spray structure.

- Practical use of the nozzle uniformity coefficient defined in the paper is related to the design of compression ignition engines. By choosing a proper combustion chamber and an intake air pipe that provides a proper value of air turbulence, the formation time of the air-fuel mixture may be reduced.

- Future research will focus on correlating the nozzle uniformity coefficient with a larger number of parameters that influence the initial structure of the fuel flow pattern at the nozzle exit using multi-criterion optimization methods.

\section{REFERENCES}

[1] European Commission: Directive 2009/28/EC of the European Parliament, http://eur-lex.europa.eu/legalcontent / EN / ALL / ? uri =CELEX\%3A32009L0028 (accessed May 2017)

[2] Roji S., Raj R., Jose D.: Experimental evaluation of performance and emission characteristics of a diesel engine fuelled with neem methyl ester, Transactions of Famena XL-3, pp.81-90, 2016. https://doi.org/10.21278/TOF.40307

[3] Taritaš I., Sremec M., Kozarac D., Blažić M., Lulic Z.: The effect of operating parameters on dual fuel engine performance and emissions - an overview, Transactions of Famena XLI-1, pp.1-14, 2017. https://doi.org/10.21278/TOF.41101

[4] Mariasiu F., Burnete N.V., Moldovanu D., Varga B.O., Iclodean C., Kocsis L.: Effects Of Bioethanol Ultrasonic Generated Aerosols Application On Diesel Engine Performances, Thermal Science 19(5), pp. 1931-1941, 2015. https://doi.org/10.2298/TSCI140703108M

[5] Tomić M., Savin L., Mićić R., Simikić M., Furman T.: Effects of fossil diesel and biodiesel blends on the performances and emissions of agricultural tractor engines, Thermal Science 17, pp. 263-278, 2013. https://doi.org/10.2298/TSCI111122106T

[6] Andsaler A.R., Khalid A., Abdullah N, Sapit A., Jaat N.: The effect of nozzle diameter, injection pressure and ambient temperature on spray characteristics in diesel engine, IOP Conf. Series: Journal of Physics: Conf. Series 822, 012039, 2017.

[7] Moon S.: Novel insights into the dynamic structure of biodiesel and conventional fuel sprays from highpressure diesel injectors, Energy 115, pp. 615-625, 2016. https://doi.org/10.1016/j.energy.2016.09.062

[8] Qiu T., Song X., Lei Y., Dai H., Cao C., Xu H., Feng X.: Effect of back pressure on nozzle inner flow in fuel injector, Fuel 173, pp. 79-89, 2016. https://doi.org/10.1016/j.fuel.2016.01.044

[9] Payri F., Payri R., Salvador F.J., Martínez-López J.: A contribution to the understanding of cavitation effects in Diesel injector nozzles through a combined experimental and computational investigation, Computers \& Fluids 58, pp. 88-101, 2012. https://doi.org/10.1016/j.compfluid.2012.01.005

[10] Park J.K., Jang J.H., Park S.W.: Effect of fuel temperature on heavy fuel oil spray characteristics in a common-rail fuel injection system for marine engines, Ocean Engineering 104, pp. 580-589, 2015. https://doi.org/10.1016/j.oceaneng.2015.06.002 
[11] Balawender K., Kuszewski H., Lejda K., Lew K.: The study on injection parameters of selected alternative fuels used in diesel engines, IOP Conf. Series: Materials Science and Engineering 148, 012070. https://doi.org/10.1088/1757-899x/148/1/012070

[12] Mariasiu F.: Numerical Investigation Of The Effects Of Biofuel Characteristics On The Injector Nozzle Erosion Process, Tribology Transactions 56(2), pp. 161-168, 2013. https://doi.org/10.1080/10402004.2012.709918

[13] Blessing M., Konig G., Kruger C., Michels U., Schwartz V.: Analysis of Flow and Cavitation Phenomena in Diesel Injection Nozzles and Its Effects on Spray and Mixture Formation, SAE International Technical Paper No. 2003-01-1358, 2003.

[14] Som S., Longman D.E., Ramirez A.I., Aggarwal, S.K.: Comparison of Injector Flow and Spray Characteristics of Biodiesel with Petrodiesel, Fuel 89, pp. 4014-4024, 2010. https://doi.org/10.1016/j.fuel.2010.05.004

Submitted: $\quad 13.10 .2017$

Accepted: $\quad 10.7 .2018$
Motogna Marius Simion, PhD student

Moldovanu Dan*, Lecturer, PhD

Dan.Moldovanu@auto.utcluj.ro Mariasiu Florin, Prof.dr.habil.

Technical University of Cluj-Napoca, Automotive Engineering and Transport Dept., Bdul.Muncii 103-105, Cluj-Napoca, Romania 